\title{
Construction of a nurse shark (Ginglymostoma cirratum) bacterial artificial chromosome (BAC) library and a preliminary genome
} survey

\author{
Meizhong Luo*1,2, HyeRan Kim¹, Dave Kudrna ${ }^{1}$, Nicholas B Sisneros ${ }^{1}$, So- \\ Jeong Lee ${ }^{1}$, Christopher Mueller ${ }^{1}$, Kristi Collura ${ }^{1}$, Andrea Zuccolo ${ }^{1}$, E \\ Bryan Buckingham ${ }^{3}$, Suzanne M Grim³ ${ }^{3}$ Kazuyo Yanagiya ${ }^{4}$, Hidetoshi Inoko ${ }^{4}$, \\ Takashi Shiina ${ }^{4}$, Martin F Flajnik ${ }^{3}$, Rod A Wing ${ }^{1}$ and Yuko Ohta*3
}

\begin{abstract}
Address: ${ }^{1}$ Arizona Genomics Institute, Department of Plant Sciences, University of Arizona, Tucson, AZ 85721, USA, ${ }^{2}$ College of Life Sciences and Technology, Huazhong Agricultural University, Wuhan 430070, China, ${ }^{3}$ University of Maryland, Department of Microbiology and Immunology, 655 West Baltimore Street, BRB3-052, Baltimore, MD 21201, USA and ${ }^{4}$ Department of Molecular Life Science, Division of Basic Medical Science and Molecular Medicine, Tokai University School of Medicine, 143 Shimokasuya, Isehara, Kanagawa 259-1143, Japan

Email: Meizhong Luo* - mzluo@mail.hzau.edu.cn; HyeRan Kim - hkim@ag.arizona.edu; Dave Kudrna - dkudrna@ag.arizona.edu; Nicholas B Sisneros - sisneros@ag.arizona.edu; So-Jeong Lee - sharlena@ag.arizona.edu; Christopher Mueller - dudemueller@ag.arizona.edu; Kristi Collura - kcollur@ag.arizona.edu; Andrea Zuccolo - azuccolo@ag.arizona.edu; E

Bryan Buckingham - bbuckingham@som.umaryland.edu; Suzanne M Grim - sgrim@som.umaryland.edu; Kazuyo Yanagiya - kazuyo-y@is.icc.utokai.ac.jp; Hidetoshi Inoko - hinoko@is.icc.u-tokai.ac.jp; Takashi Shiina - tshiina@is.icc.u-tokai.ac.jp;

Martin F Flajnik - mflajnik@som.umaryland.edu; Rod A Wing - rwing@ag.arizona.edu; Yuko Ohta* - yota@som.umaryland.edu

* Corresponding authors
\end{abstract}

Published: 03 May 2006

BMC Genomics 2006, 7:106 doi:10.1186/147|-2164-7-106
Received: 24 December 2005

Accepted: 03 May 2006

This article is available from: http://www.biomedcentral.com//47/-2/64/7//06

(c) 2006 Luo et al; licensee BioMed Central Ltd.

This is an Open Access article distributed under the terms of the Creative Commons Attribution License (http://creativecommons.org/licenses/by/2.0), which permits unrestricted use, distribution, and reproduction in any medium, provided the original work is properly cited.

\begin{abstract}
Background: Sharks are members of the taxonomic class Chondrichthyes, the oldest living jawed vertebrates. Genomic studies of this group, in comparison to representative species in other vertebrate taxa, will allow us to theorize about the fundamental genetic, developmental, and functional characteristics in the common ancestor of all jawed vertebrates.

Aims: In order to obtain mapping and sequencing data for comparative genomics, we constructed a bacterial artificial chromosome (BAC) library for the nurse shark, Ginglymostoma cirratum.

Results: The BAC library consists of 313,344 clones with an average insert size of $144 \mathrm{~kb}$, covering $\sim 4.5 \times 10^{10} \mathrm{bp}$ and thus providing an II-fold coverage of the haploid genome. BAC end sequence analyses revealed, in addition to LINEs and SINEs commonly found in other animal and plant genomes, two new groups of nurse shark-specific repetitive elements, NSREI and NSRE2 that seem to be major components of the nurse shark genome. Screening the library with single-copy or multi-copy gene probes showed 6-28 primary positive clones per probe of which $50-90 \%$ were true positives, demonstrating that the BAC library is representative of the different regions of the nurse shark genome. Furthermore, some BAC clones contained multiple genes, making physical mapping feasible.
\end{abstract}

Conclusion: We have constructed a deep-coverage, high-quality, large insert, and publicly available BAC library for a cartilaginous fish. It will be very useful to the scientific community interested in shark genomic structure, comparative genomics, and functional studies. We found two new groups of repetitive elements specific to the nurse shark genome, which may contribute to the architecture and evolution of the nurse shark genome. 


\section{Background}

Bacterial artificial chromosome (BAC) libraries are indispensable for many applications in genomic studies [1-3]. BAC-end sequences have been used to develop sequencetagged connector (STC) frameworks [4,5], to survey genome structures [6], and for comparative analysis of gene structure and synteny. Although the whole-genome shotgun method has been used to produce genome draft sequences [7], mapped BACs usually have been required to provide a framework for sequence assembly and templates to complete the sequences of complex genomes $[3,5,8]$. BACs and BAC-based maps have also been used in sequencing of targeted genome regions [9], chromosomal landing or positional cloning [10], genome function investigation [11], and evolutionary and comparative studies [12]. Through BAC sequencing, a full-length avian androgen receptor gene was identified, which had not been detected with conventional methods [13].

Sharks belong to the phylogenetic taxon comprising the oldest jawed vertebrates, the cartilaginous fish, which diverged from the common ancestor of all other jawed vertebrates 460-520 million years ago [14]. Genomic and genetic studies of this group, in comparison to representative species in other vertebrate taxa, will allow us to theorize about the fundamental genetic, developmental, and functional characteristics in the common ancestor of all jawed vertebrates. This ancient taxon is of particular interest to us since it is the oldest group of living animals having an adaptive immune system with underlying molecules and mechanisms similar to those of mammals [15]. While most sharks and other cartilaginous fish have large genome sizes ( $~ 80 \%$ of species studied have larger genome sizes than human, with some up to 5 times as large), the nurse shark genome size is relatively small at 4 $\times 10^{9} \mathrm{bp} /$ haploid genome, only slightly larger than that of humans $\left(3.4 \times 10^{9}\right)$. Thus, the nurse shark is a candidate to become a model species in the biomedical and genomics fields. However, most of the shark genes and intergenic regions are much larger than those of mammals, and thus large-insert genomic libraries are essential to obtain sufficient genomic information. Previously, BAC libraries of other cartilaginous fish (clearnose skate and horn shark)were described by Miyake and Amemiya [1]. In this paper we report the construction and characterization of a publicly-available nurse shark BAC library and carry out a preliminary genome survey.

\section{Results and discussion BAC library construction}

We constructed a nurse shark BAC library, consisting of a total of 313,344 clones that were deposited in 816 barcode-ordered 384-well microtiter plates. To complete this large library, approximately 20 ligations were performed. Since colonies with a diameter of $<1.5 \mathrm{~mm}$ did not grow well in the freezing media, only those colonies with a diameter of $>1.5 \mathrm{~mm}$ on selection-agar plates were picked.

\section{Insert size distribution}

To evaluate the quality of the BAC library, we first analyzed the insert sizes of 408 sampling BAC clones with Not I (cutting GCGGCCGC sequence), which liberates the inserts from the BAC vector (Figure 1). The 408 sampling $\mathrm{BAC}$ clones were selected by picking one clone from A01 position of every other 384-well plate of the library and arranged in the same order as the library plates. Of the 408 BAC clones, 6 did not yield detectable DNA. Of the remaining 402 clones, only one had no insert, indicating a negligible empty-vector rate (1/402). While most clones produced only one Not I insert band, $16 \%$ of the clones produced more than one insert band due to the presence of internal Not I sites. Eight such clones produced a single or very few small insert bands with high DNA densities disproportional to the DNA density of the vector band, suggesting co-migration of multiple repetitive bands. In fact, when these clones were digested with Swa I (cutting ATTTAAAT sequence) that also liberates the inserts, they generated single large-insert bands (e.g. $194 \mathrm{~kb}$ ). These clones may be of interest because they might contain large repetitive and structurally distinctive regions with extremely high GC content. The average insert size of the 402 clones is $144 \mathrm{~kb}$, and thus the entire BAC library covers $\sim 4.5 \times 10^{10}$ bp $(313,344 \times 144,000 \mathrm{bp})$. The nurse shark genome content was reported to be $\sim 8$ pg DNA per cell [16], $4 \times 10^{9}$ bp per haploid genome. Thus, our BAC library covers $\sim 11$ haploid genome equivalents. Approximately $94 \%$ of clones contain inserts greater than $110 \mathrm{~kb}$. Although multiple ligations were used, no significant difference was observed between different library segments corresponding to the different ligations except that one segment of 14,976 clones, corresponding to the library plates 628 to 666 (number 314 to 333 in Figure 1), has very large inserts. This segment resulted from two parallel ligations and has an average insert size of $209 \mathrm{~kb}$.

\section{$B A C$ end sequence analysis}

We sequenced the first 96 of the above 408 sampling clones at both ends. One hundred seventy-seven BAC end sequences (BES) were obtained with an average highquality base-pair (bp) number of 548 bp ([GenBank:CZ549372 CZ579549], excluding [GenBank:CZ549507] which is the vector sequence), covering a total of $\sim 100,000 \mathrm{bp}$. The average GC content of the BES is $41 \%$, ranging from $26-66 \%$. Sequences from other parts of the nurse shark genome ( $300 \mathrm{~kb})$ have an average of $42-45 \%$ GC content (YO, MFF; personal observation), which is consistent with this finding. It is worth noting that the GC content was calculated in windows of the BES lengths, and some smaller regions may contain higher GC content. Indeed, we previously detected simple 


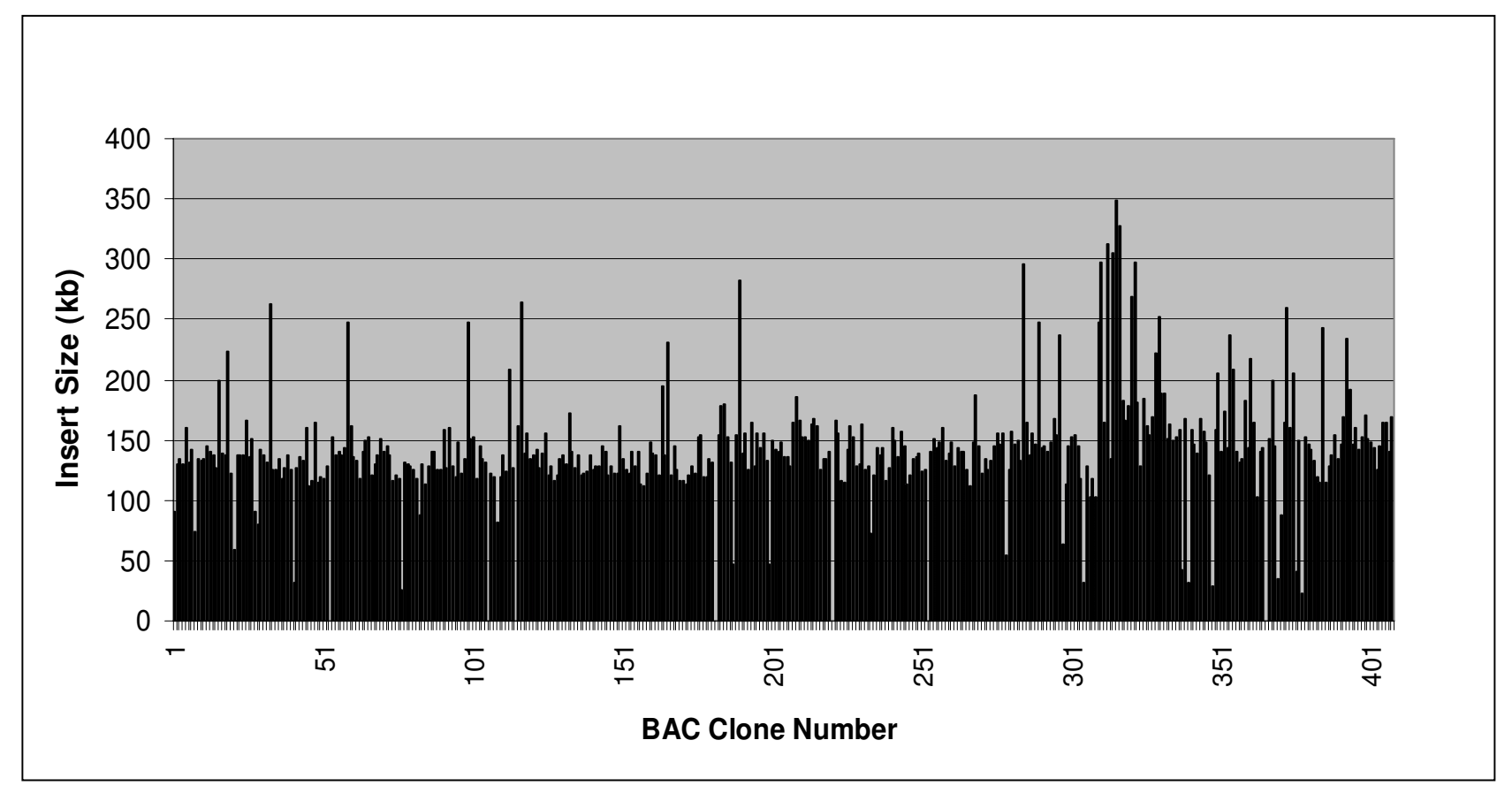

Figure I

Insert size distribution of the 408 sampling BAC clones. The 408 sampling BAC clones were selected by picking one clone from A0I position of every other 384-well plate of the library and arranged in the same order of the library plates. Vertical bars indicate the sampling clones with inserts. The clones that failed to yield DNA or do not contain inserts are represented by blanks.

repeats with a high GC content (70-80\%) in a region of the Major Histocompatibility Complex (MHC) class I gene [17]. Analysis of the BES also revealed 4 sequences containing significantly long microsatellite repeats (simple sequence repeats, SSRs): [GenBank:CZ549546] (AG) [GenBank:CZ549467] (AG) ${ }_{19}$, [GenBank:CZ549532] $(\mathrm{AT})_{9}$ and [GenBank:CZ549547] (AC) ${ }_{14}$. However, no significant tri-nucleotide or longer motifs of SSRs were found in our BES. The CpG dinucleotide frequency was underrepresented (the observed value is only $1 / 4$ of the expected one) while the AA and TT dinucleotide frequencies were over-represented in this set of BES.

BlastN and BlastX searches of these BES against the 'nr' database in GenBank and tBlastX and tBlastN searches against an in-house collection of conserved domains of non-LTR retroelements were carried out with an E-value of below 1e-10. The Blast analysis results are classified in Table 1 (BlastN results can be found in our web site [18]). Nine BES share a significant similarity with various shark genomic sequences; one [GenBank:CZ549423] is similar to $18 \mathrm{~S}$ ribosomal RNA; two showed hits to zebrafish and Tetraodon genomic sequences that remain 'unclassified'; and one hundred and two showed 'No Hits'. Twenty-nine and five BES contained LINEs and SINEs respectively, indicating that these repetitive elements are major components of the nurse shark genome. Most of them hit regions of published nurse shark genomic sequences, especially to an intron of the LMP7-like pseudogene, and non-coding sequences from genes in other shark species (RAG [19] and $\operatorname{HOX}[20]$ ), and the 3'-untranslated region (3'UTR) of a non-classical class I gene, UAA-NC1 [17] that contains a retrotransposon. Most of the LINEs contain partial open reading frames (ORFs) encoding reverse transcriptases related to the CR1 family, first found in chicken [21]. The high representation of CR1-like SINEs/LINEs is thus likely to be a common feature of shark genomes. In the sandbar shark (Carcharhinus plumbeus), a total of 7 CR1-like SINE/ LINE elements were found in the $9.4 \mathrm{~kb}$ intergenic region of RAG1 and RAG2 [22].

\section{NSREI and NSRE2 analysis}

The remaining 29 BES and one other [GenBank:CZ549472] that also contains a LINE element are of interest. They hit only nurse shark BAC draft sequences when searched against 'htgs' (high-throughput genomic 
sequence) database in GenBank. When BlastN searches were performed using the whole BES set as the database and the BES as queries, they were categorized into two groups designated as NSRE1 (nurse shark repetitive element 1) and NSRE2 (24 and 6 for NSRE1 and NSRE2 respectively, Figures 2 and 3 ). Searching against the 'nr' database in GenBank revealed that 21 of 24 NSRE1 sequences hit the nurse shark UAA-NC1 cDNA ([GenBank:AF357922]) in the 5'UTR (nt positions 2-103), and 22 of 24 NSRE1 sequences hit the nurse shark LMP7 pseudogene, exon 4 ([GenBank:AF357928]) at nt positions 3274-3350 (see Additional file 1). The $698 \mathrm{bp}$-sequence of GC_Ba0153A01.f [Genbank:CZ549510] hit the subject regions in two query regions (nt positions 1-60 and 538635), showing two NSRE1 in one BES. Two BAC clones (GC_Ba0143A01 and GC_Ba0109A01) hit the subject regions at both ends. When the subject sequence [GenBank: $\underline{\text { AF357922] }}$ nt positions 2-103 region was used as a query to search the 'htgs' database in GenBank, it only hit all the 9 nurse shark BAC draft sequences then present in the GenBank in multiple regions with an average of 7.2 hits/BAC, from a minimum of 3 to a maximum of 11 (data of Oct. 2, 2005). Searching the NSRE2 sequence [GenBank:CZ549534] against the 'htgs' database in GenBank found an average of 3.4 hits/BAC on 8 of the 9 nurse shark BAC draft sequences ranging from a minimum of 1 to a maximum of 5. These results indicate that NSRE1 and NSRE2 are repetitive elements, and NSRE1 is more frequent in the nurse shark genome than NSRE2. BlastX searches of both NSRE1 and NSRE2 did not detect any protein matches. To further sample the representation and organization of NSRE1 and NSRE2 elements in the nurse shark genome including coding and non-coding regions, we sequenced the BAC clone GC_Ba0754I06. The draft sequence of this clone revealed seventeen NSRE1 and six NSRE2 in a $\sim 170 \mathrm{~kb}$ region dispersed among SINEs/LINEs repetitive elements. All identified repetitive elements are found most abundantly in regions outside of the gene (e.g. fatty acid synthase FASN, Figure 4).

To confirm that these repetitive sequences were present in a high copy number in the nurse shark genome and to test for their existence in related animals, we did Southern blotting and library screening using 'overgo' probes of NSRE1 and NSRE2. Both the NSRE1 and NSRE2 probes hybridized to the nurse shark genomic DNA, but not to DNA from other elasmobranchs (sand tiger shark, little skate, and lemon shark), Xenopus laevis, rat, human and zebra finch (Figure 5 for NSRE1, data not shown for NSRE2). Both the NSRE1 and NSRE2 hybridization signals are smear, indicating that these elements are highly repetitive and dispersed in the nurse shark genome, consistent with our sequence analysis results above. From a library screening of 36,864 clones, many colonies hybridized with different intensities (data not shown), perhaps correlating with the copy numbers within the BAC clones. Our data suggest that the expansion of NSRE1 and NSRE2 repetitive elements occurred after the divergence of nurse shark from other shark lineages. However, we examined only distantly related shark species in this study. Closely related shark species, belonging to the same family (Orectolobiformes) as nurse shark (e.g. wobbegong shark, bamboo shark), must be examined for the presence/absence of these repetitive elements. It is possible that different, unique repetitive elements will be found in other shark species.

\section{NSRE1}
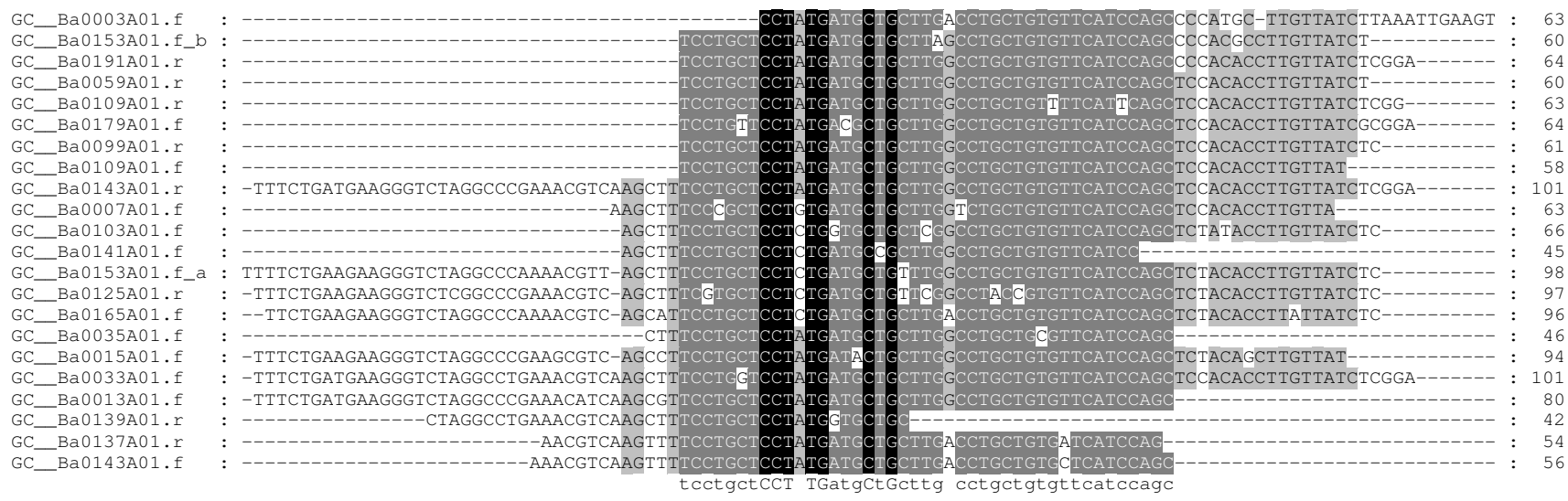

Figure 2

NSREI analyses. NSREI core nucleotide sequences were aligned using ClustalW. GC_Ba0I53A0I.f sequence contains two NSRE I elements (marked as a and b). Shaded color correlates the degree of nucleotide conservation (e.g. black; identical in all sequence). Consensus sequences are shown under the alignment in lower cases. 


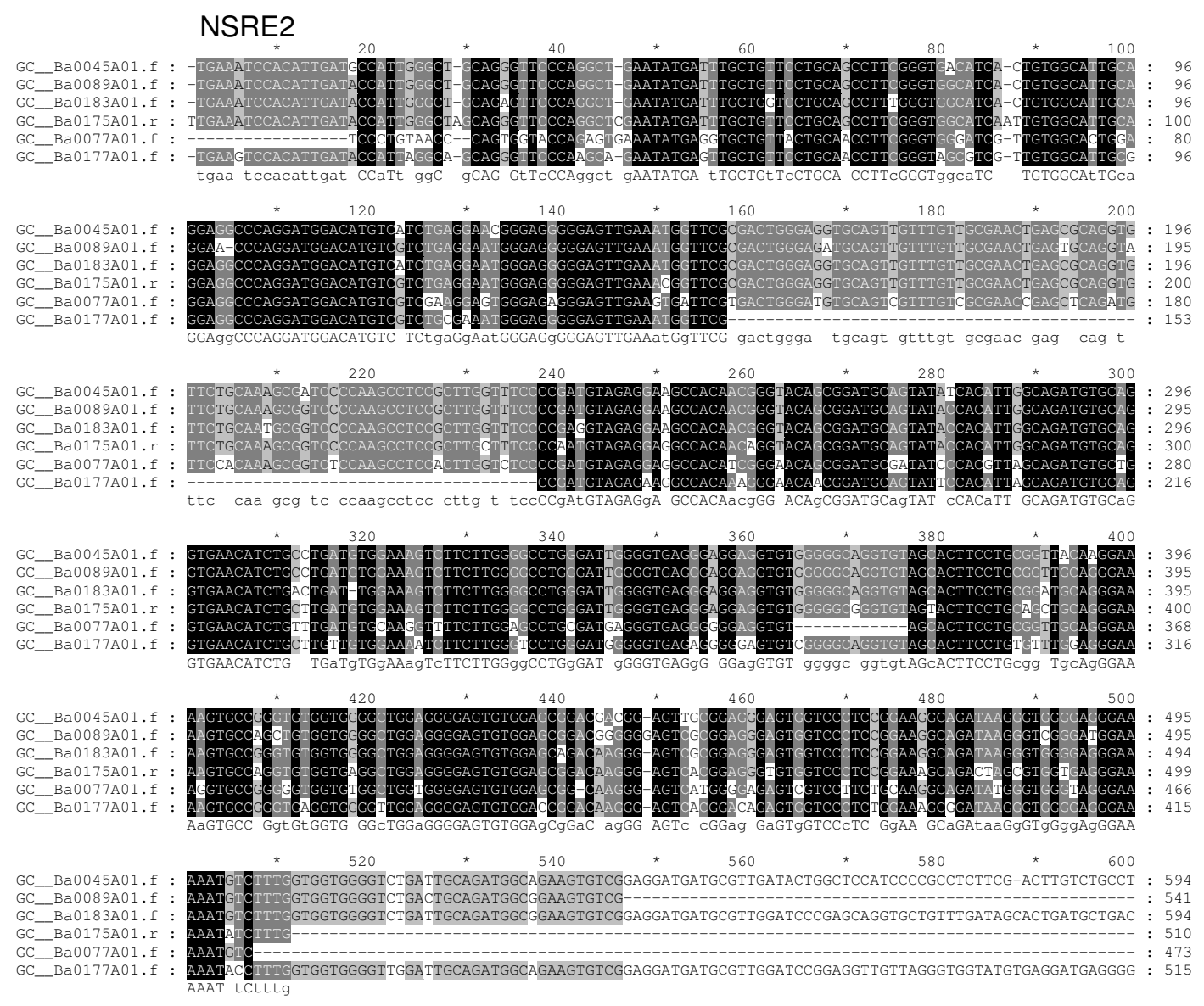

Figure 3

NSRE2 analysis. NSRE2 full-length BES sequences were aligned using ClustalW. Shaded color correlates the degree of nucleotide conservation (e.g. black; identical in all sequence). Consensus sequences are shown under the alignment in lower cases.

\section{BAC library screening with gene-specific probes}

To further assess the quality and demonstrate the utility of the BAC library, we screened the entire BAC library with gene-specific probes. These probes are listed in Table 2. With all single-copy gene probes except TAP1 (transporter associated with antigen processing) and Ring3, we obtained 6-28 positive clones (Table 2, library screening). A similar number of positive clones was observed when we used the Factor $B$ probe, present in two tandem copies in the nurse shark genome. We further confirmed the positive clones by colony hybridization (Table 2, colony hybridization). Most of the gene probes except CD83 [23] resulted in 8-19 true positives, consistent with the $11 \mathrm{x}$ coverage calculated from the average insert size and total number of clones. The low percentage (50\%) of true positives from MHC class I and CD83 may be due to weakly hybridizing false-positives, which appeared only after long film exposures. In some cases, we observed multiple weaker signals in the vicinity of the stronger signals in the same double-spotting pattern, presumably due to carryover during filter production. In fact, the low percentage $(62 \%)$ of true positives for the TAP1 probe was most probably due to such carryover of positive clones into neighboring wells. Once we carefully selected putative positive clones for TCR probes (i.e. only selected the strongest signals among the neighboring signals), the percentage of true positives increased (see Table 2, 89-91\% TCRs). TAP1 and Ring 3 are members of large gene families containing conserved domains, which might cross-hybridize to other family members and thus result in higher number of positive clones than expected. With the LMP7 probe, 19 positive clones seem to be low for a multi-copy gene, however we have found at least 2 pseudogenes containing only small fragments of the gene [17]. These results 


\section{GC_Ba0754106}

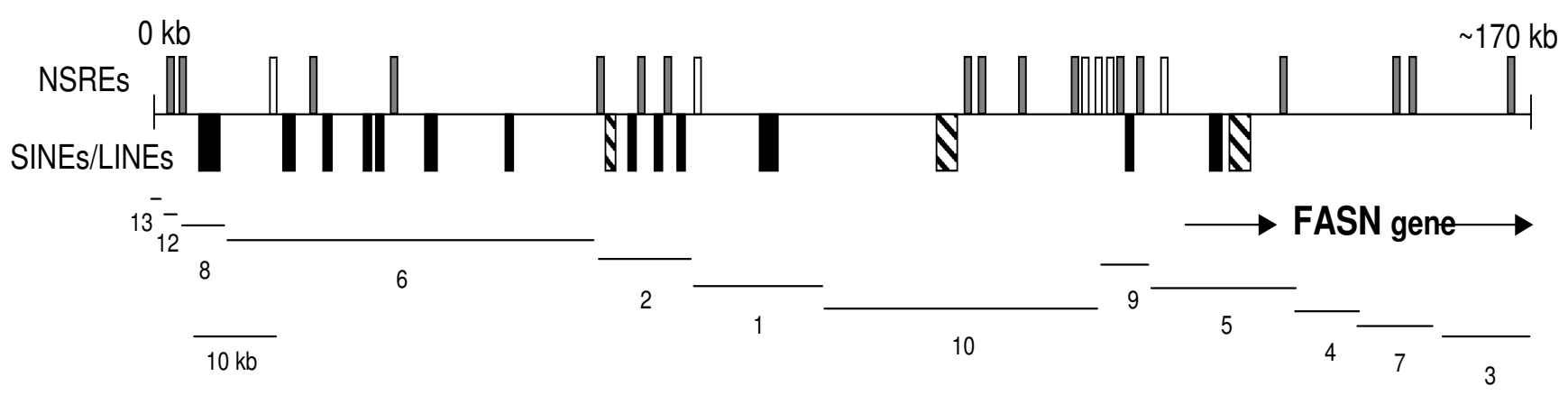

Figure 4

NSREI (top, gray box) and NSRE2 (top, open box) were mapped on the draft sequence of the BAC clone GC_Ba0754I06 along with SINEs/LINEs (bottom, hatched box) and CRI-like SINEs/LINEs (bottom, black box). Transcriptional orientation of a partial fatty acid synthase (FASN) gene, including at least 27 exons, is marked with arrows from $5^{\prime}$ to $3^{\prime}$ direction. Contigs and their numbers are shown under the map. A $10 \mathrm{~kb}$ scale is shown on the left bottom.

showed that most genetic regions tested in this study (except $C D 83$ ) were well represented in the BAC library.
Unlike most other species, the nurse shark MHC genes are much (3-5 times) larger than those of mammals and have even larger distances in intergenic regions [17]. Previ-

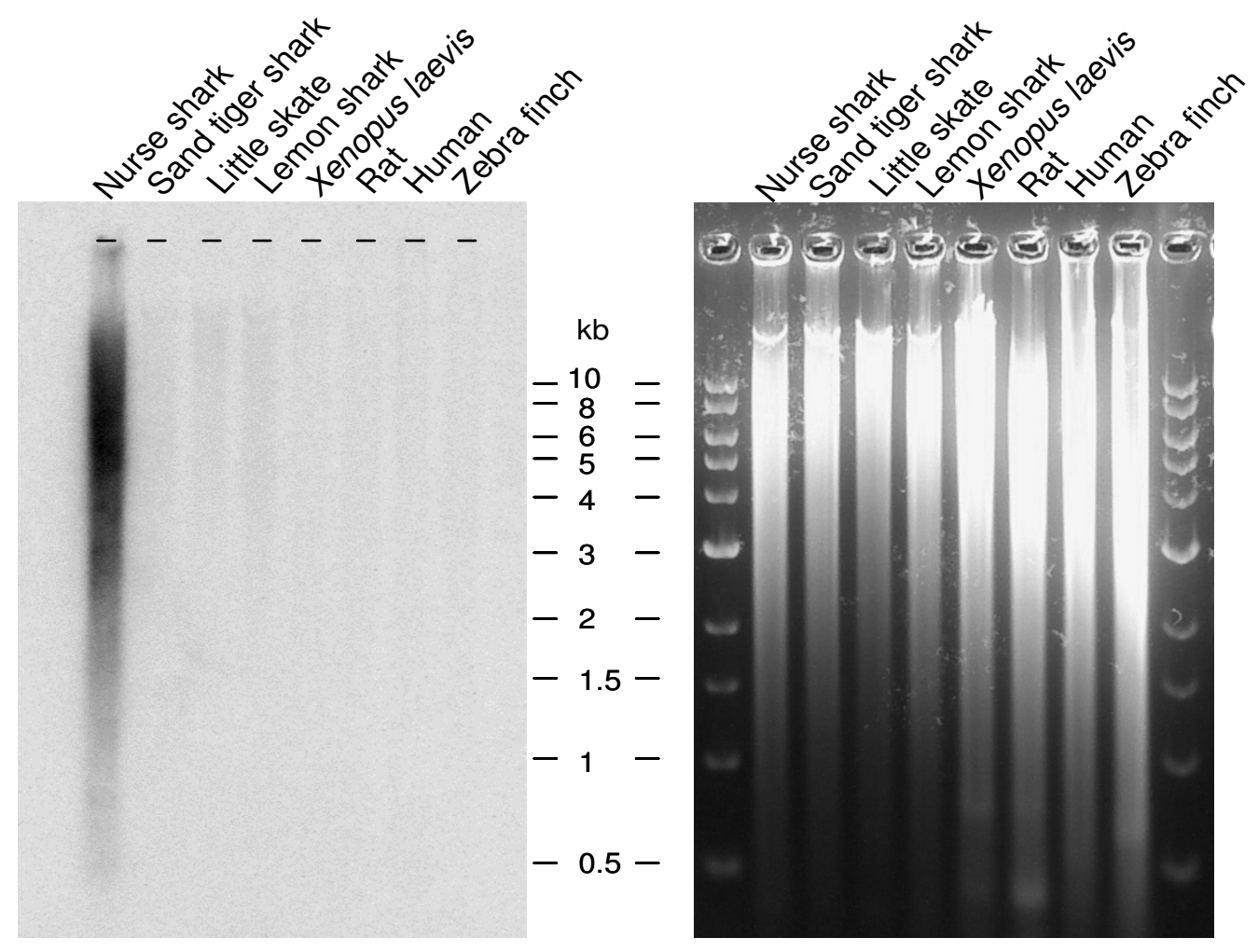

\section{Figure 5}

Southern blotting with the NSREI 'overgo' probe. Genomic DNAs from various species (denoted at the top of the blot) were digested with Hin dIII and separated on an agarose gel. The I kb size standards were loaded on both sides of the gel. The ethidium bromide-stained image is shown as a loading control on the right of the blot. 
Table I: The classification of BES.

\begin{tabular}{ll}
\hline Classification & Number of BES \\
\hline LINE & 29 \\
SINE & 5 \\
NSREI & 24 \\
NSRE2 & 6 \\
Shark genomic & 9 \\
I8S Ribosomal & 1 \\
Unclassified & 2 \\
No Hits & 102 \\
Total & $177^{*}$ \\
\hline
\end{tabular}

* One BES contains both LINE and NSREI.

ously, we constructed a genomic cosmid library with an average insert size of $\sim 40 \mathrm{~kb}$. However, most cosmid clones contain at most a single gene (data not shown). In this study, we used several linked genes (TAP1, MHC class I, class II, Factor B, LMP7, LMP2 [17,24], and Ring3 (unpublished data)) to quickly glean the number of genes

gle BAC clone, making physical mapping possible. Thus far, our analysis has convincingly shown that the BAC library is a useful tool (and perhaps the only way) to obtain genetic information for this species.

\section{Conclusion}

Table 2: Number of gene-specific clones in the nurse shark BAC library Single copy genes.

\begin{tabular}{|c|c|c|c|c|}
\hline \multicolumn{5}{|c|}{ Single copy genes } \\
\hline \multirow[b]{2}{*}{ Genes } & \multicolumn{2}{|c|}{ Number of positive clones } & \multicolumn{2}{|l|}{$\%$} \\
\hline & Library Screening & Colony hybridization & Colony hyb./Library scr. & References \\
\hline TAPI & 60 & 37 & $62 \%$ & [17] \\
\hline Ring3 & 72 & 62 & $86 \%$ & Unpublished \\
\hline MHC class I & 20 & 10 & $50 \%$ & [17] \\
\hline CD83 & 6 & 3 & $50 \%$ & [23] \\
\hline Gici-II* & 28 & 19 & $68 \%$ & [37] \\
\hline LMP2 & 18 & NA & NA & {$[17]$} \\
\hline TCR $\beta$ & 9 & 8 & $89 \%$ & Unpublished \\
\hline TCR $\delta$ & 11 & 10 & $91 \%$ & Unpublished \\
\hline \multicolumn{5}{|c|}{ Possibly two genes in tandem or close vicinity } \\
\hline Genes & Library screening & Colony hybridization & Colony hyb./Library scr. & References \\
\hline MHC class II $\alpha$ & 14 & 12 & $86 \%$ & [39] \\
\hline MHC class $I I \beta$ & 13 & 9 & $69 \%$ & {$[40]$} \\
\hline Factor B & 16 & 14 & $87 \%$ & {$[24]$} \\
\hline \multicolumn{5}{|l|}{ Multiple genes } \\
\hline Genes & Library screening & Colony hybridization & Colony hyb./Library scr. & References \\
\hline LMP7** & 41 & 19 & $46 \%$ & {$[4 I]$} \\
\hline
\end{tabular}

NA: not available

*several genes, but our 3'UTR specific probe only identifies one gene

$* *$ only one complete and functional gene (i.e. many pseudogenes)

in a single BAC clone; we found up to four genes in a sin- 
We report in this paper a large insert, deep-coverage and high-quality BAC library for a cartilaginous fish that will be very useful to the scientific community for gene isolation, genetic analysis, and comparative genomics. We found two new groups of repetitive elements, designated as NSRE1 and NSRE2, which are specific to the nurse shark genome. These repetitive elements may contribute to the architecture and evolution of the nurse shark genome. The BAC library, HDR filters and individual clones are available to the public from the Arizona Genomics Institute's BAC/EST Resource Center [18].

\section{Methods}

\section{Isolation of high molecular weight DNA}

Blood was obtained from the nurse shark individual "Yellow" using a Heparinized 18G 1 1/2" needle from the caudal vein. To obtain 30 micrograms of DNA per $80-\mu l$ agarose plug, approximately $4 \times 10^{6}$ erythrocytes were embedded in 1\% InCert agarose (FMC, Rockland, ME) prepared in 1/2x PBS and molded in 200 Plug Molds (BIO-RAD, Hercules, CA). Twenty plugs were then submerged in $50 \mathrm{ml}$ of cell lysis solution (1\% lithium dodecyl sulfate, $10 \mathrm{mM}$ Tris, pH8.0, $100 \mathrm{mM}$ EDTA, pH8.0) and incubated overnight at $37^{\circ} \mathrm{C}$ with occasional swirling. The cell lysis solution was replaced with $50 \mathrm{ml} \mathrm{20 \%} \mathrm{NDS}$ (0.2\% N-lauroylsarcosine, $2 \mathrm{mM}$ Tris, pH9.0, 0.14M EDTA, pH9.0), and DNA plugs were shaken gently at room temperature for two hours, and then kept at $4^{\circ} \mathrm{C}$ [25].

\section{BAC vector preparation}

We used a modified version of the BAC vector pBeloBAC11, pIndigoBAC536Swa. A first modified version of pBeloBAC11 [GenBank:U51113], pIndigoBAC536, was a gift from Dr. H. Shizuya of Caltech. pIndigoBAC536 has the internal Eco R1 site of pBeloBAC11 destroyed so that the unique Eco R1 site in the multiple cloning sites can be used for cloning, and also contains a random point mutation in the lac $\mathrm{Z}$ gene that provides colonies with a darker blue-color on X-gal/ IPTG selection. We further inserted two Swa I sites (ATTTAAAT) near and internal to the two Not I sites of pIndigoBAC536 (this new version is named pIndigoBAC536Swa) to facilitate insert-size estimation of clones from GC-rich organisms (Luo et al, unpublished data). We then cloned this single-copy BAC vector pIndigoBAC536Swa into the high-copy vector pGEM-4Z (this composed high-copy plasmid is named pAGIBAC1) to facilitate the preparation of the single-copy $\mathrm{BAC}$ vector as we did for pIndigoBAC536 (the composed high-copy pIndigoBAC536-pGEM-4Z plasmid is named pCUGIBAC1) [26]. pCUGIBAC1 is available through Clemson University Genomics Institute [27] and pAGIBAC1 is available through Arizona Genomics Institute [18]. The linearized and dephosphorylated single- copy BAC vector pIndigoBAC536Swa can be prepared from the high-copy pAGIBAC1 according to our previously published method [28].

\section{Generation and size selection of large DNA fragments for BAC cloning}

Large genomic DNA fragments for BAC cloning were prepared according to our previously published method [28]. The DNA-agarose plugs were washed thoroughly with TE buffer (10 mM Tris/1 mM EDTA, pH8.0) and stored in $70 \%$ ethanol at $-20^{\circ} \mathrm{C}$. A desired number of DNA plugs were transferred to TE buffer the day before use and kept at $4{ }^{\circ} \mathrm{C}$ overnight. The DNA plugs were test-digested with various amount of Hin dIII (1-50U) for 20 minutes at $37^{\circ} \mathrm{C}$ to optimize partial digestion conditions and the fragmented DNAs were separated on 1\% agarose gels by Pulsed Field Gel Electrophoresis (PFGE) (CHEF Mapper, BIO-RAD) at $1-50 \mathrm{sec}$ linear ramp, 6 volts $/ \mathrm{cm}, 14^{\circ} \mathrm{C}$ in 0.5X TBE buffer for 18-20 hours. Bulk digestions were then carried out using the conditions that produced the most DNA fragments in the range of 100-400 kb. Fragmented DNAs were separated on a $1 \%$ CHEF gel in the same conditions described above. DNA fractions ranging from $150-250 \mathrm{~kb}$ and $250-350 \mathrm{~kb}$ were excised from the gel and subjected to a second size selection on a $1 \% \mathrm{CHEF}$ gel at $4 \mathrm{sec}$ constant time, 6 volts $/ \mathrm{cm}, 14^{\circ} \mathrm{C}$ in $0.5 \mathrm{X}$ TBE buffer for 18-20 hours. DNA fragments were electroeluted with dialysis tubing as described by Strong et al [29] or with an Electro-eluter Model 422 (BIO-RAD) following the manufacture's instructions. DNA concentrations were determined on subsequent agarose gels.

\section{Ligation and transformation}

One hundred to two hundred nanograms of size-selected DNA fragments were ligated with 20 nanograms of dephosphorylated BAC vector in a $100 \mu$ l of volume at $16^{\circ} \mathrm{C}$ overnight. The ligation reactions were terminated at $65^{\circ} \mathrm{C}$ for $15 \mathrm{~min}$, and the ligation products were desalted in $0.1 \mathrm{M}$ glucose : $1 \%$ agarose cones for 1.5 hours on ice as described by Atrazhev and Elliott [30] and electroporated into the E. coli strain DH10B T1 phage resistant (FmcrA $\Delta$ (mrr-hsdRMS-mcrBC) $\phi 80 d l a c Z \quad \Delta$ M15 $\Delta l a c X 74$ deo $\mathrm{R}$ recA1 end 1 araD139 $\Delta($ ara, leu $) 7697$ galU galK $\lambda$ $r p s \mathrm{~L} n p \mathrm{G}$ ) electrocompetent cells (Invitrogen, Carlsbad, CA). Transformants were grown on LB plates supplemented with $12.5 \mathrm{mg} / \mathrm{L}$ chloramphenicol, $80 \mathrm{mg} / \mathrm{L} \mathrm{X-gal}$ (5-bromo-4-chloro-3-indolyl-beta-D-galactoside or 5bromo-4-chloro-3-indolyl-beta-D-galactopyranoside) and $100 \mathrm{mg} / \mathrm{L}$ IPTG (Isopropyl-beta-D-thiogalactoside or Isopropyl-beta-D-thiogalactopyranoside) at $37^{\circ} \mathrm{C}$ overnight.

\section{Library arraying and high density replica (HDR) filters}

A total of 313,344 individual recombinant clones (white color on X-gal plates) were picked robotically (Genetix, 
New Milton, UK) and arrayed into 816 barcode-ordered 384-well microtiter plates containing freezing media (10 $\mathrm{g} / \mathrm{L}$ Bacto tryptone, $5 \mathrm{~g} / \mathrm{L}$ Bacto yeast extract, $10 \mathrm{~g} / \mathrm{L} \mathrm{NaCl}$, $36 \mathrm{mM} \mathrm{K}_{2} \mathrm{HPO}_{4}, 13.2 \mathrm{mM} \mathrm{KH} \mathrm{PO}_{4}, 1.7 \mathrm{mM}$ Na-citrate, $6.8 \mathrm{mM}\left(\mathrm{NH}_{4}\right)_{2} \mathrm{SO}_{4}, 4.4 \%$ glycerol, autoclaved and added filter-sterilized $\mathrm{MgSO}_{4}$ solution to the final concentration of $0.4 \mathrm{mM}$ ) supplemented with $12.5 \mathrm{mg} / \mathrm{L}$ of chloramphenicol. After an overnight incubation at $37^{\circ} \mathrm{C}$, empty wells were back-filled manually and duplicate copies were replicated. The master library and the two copies were then stored in $-80^{\circ} \mathrm{C}$ freezers at different locations. The whole BAC library was gridded onto $1722.5 \mathrm{~cm} \times 22.5 \mathrm{~cm}$ Hybond $\mathrm{N}+$ membrane filters (Amersham, Piscataway, $\mathrm{NJ}$ ) in high density, double spots, and $4 \times 4$ patterns with Genetix Q-bots (Genetix). Each $22.5 \mathrm{~cm} \times 22.5 \mathrm{~cm}$ filter supports 18,432 clones in duplicate in 6 fields. The filters were placed on LB media supplemented with $12.5 \mathrm{mg} / \mathrm{L}$ of chloramphenicol and incubated overnight at $37^{\circ} \mathrm{C}$. The filters were then soaked in $0.5 \mathrm{~N} \mathrm{NaOH} / 1.5 \mathrm{M} \mathrm{NaCl}$ for $7 \mathrm{~min}$, in $1.5 \mathrm{M} \mathrm{NaCl} / 0.5 \mathrm{M}$ Tris- $\mathrm{HCl}$ (pH8) for $7 \mathrm{~min}$, air dried for $1-2$ hours, soaked in $0.4 \mathrm{~N} \mathrm{NaOH}$ for $20 \mathrm{~min}$, in 20x SSPE for $7 \mathrm{~min}$, and air-dried overnight.

\section{DNA analysis of BAC clones}

BAC DNAs were extracted with Tomtec Quadra 96 model 320 (Tomtec, Hamden, CT) in a 96-well format at AGI. The 408 sampling BAC clones were selected by picking one clone from A01 position of every other 384-well plate of the library and arranged in the same order of the library plates. Inserts were liberated by digesting with Not I or Swa I and their sizes were determined on CHEF gels.

\section{$B A C$ end sequencing}

BAC DNAs were sequenced at both ends using BigDye Terminator v.3 (Applied Biosystems, ABI, Foster City, CA) according to manufacturer's instruction. The T7 primer (5' TAA TAC GAC TCA CTA TAG GG 3') was used as the "forward" primer and the BES_HR primer (5' CAC TCA TTA GGC ACC CCA 3') was used as the "reverse" primer. Cycle sequencing was performed using PTC-200 thermal cyclers (MJ Research, Waltham, MA) in a 384-well format with the following regime: 150 cycles of $10 \mathrm{sec}$ at $95^{\circ} \mathrm{C}, 5 \mathrm{sec}$ at $55^{\circ} \mathrm{C}$, and $2.5 \mathrm{~min}$ at $60^{\circ} \mathrm{C}$. After the cycle-sequencing step, the DNA was purified by magnetic beads, CleanSeq (Agencourt, Beverly, MA) according to manufacturer's instruction. Samples were eluted into $20 \mu \mathrm{l}$ of water and separated on ABI 3730xl DNA capillary sequencers with default conditions. Sequence data was collected by data collection software (Applied Biosystems), extracted using sequence analysis software (Applied Biosystems) and transferred to a UNIX workstation. Sequences were basecalled using the program Phred [31,32]; vector and lowquality (Phred value $<16$ ) sequences were removed by CROSS_MATCH $[31,32]$.

\section{Bioinformatics analyses of sequences}

Similarity searches against public GenBank and in-house database were carried out using the Blast algorithm. Composition analyses as well as searches for inverted repeats were done using the programs "composition" and "palindrome" respectively, both of which are included in the package EMBOSS [33]. SSR were searched using the software "Sputnik" [34].

\section{NSRE alignment}

The nucleotide sequences of both NSRE1 and NSRE2 were aligned using ClustalW. NSRE1 motifs were extracted from BES and full-length BES sequences were aligned for NSRE2.

\section{Southern blotting for NSREs}

Five $\mu \mathrm{g}$ genomic DNAs were digested with 80 units of restriction enzyme Hin dIII for 6 hours at $37^{\circ} \mathrm{C}$. DNA fragments were separated in a $0.8 \%$ agarose gel by electrophoresis and blotted onto a nylon membrane. Overlapping oligonucleotide (overgo) hybridization was performed according to Ross et al [35] with modifications. The NSRE1 and NSRE2 overgo probes were designed from the sequence [GenBank:AF357922] nt positions 2-103 region and sequence [GenBank: $\underline{\text { AF357928] }}$ nt position 4406-4529 region respectively. Primers used for NSRE1 are: 5' TCT CGG CCC GAA ACG TCA GCT TTC 3' and 5' AGC ATC AGA GGA GCA CGA AAG CTG 3'. Primers used for NSRE2 are: 5' TGC TGT TCC TGC AAC CTT CGG GTA 3' and 5' AAT GCC ACA ACG ACG CTA CCC GAA 3'. Each set of primers overlaps by 8 base pairs. Probes were labeled with both ${ }^{32} \mathrm{P}$-dCTP and ${ }^{32} \mathrm{P}$-dATP using Klenow enzyme. Hybridization was carried out overnight in a solution containing 1\% Bovine Serum Albumin (BSA), 1 mM EDTA pH8.0, $7 \%$ SDS, $0.5 \mathrm{M}$ sodium phosphate at $60^{\circ} \mathrm{C}$. Membranes were washed in $4 \mathrm{x}$ SSC, $0.1 \%$ SDS at room temperature, followed by $1.5 \mathrm{x}$ SSC, $0.1 \%$ SDS at $60^{\circ} \mathrm{C}$. Membranes were exposed to screens and scanned using the phosphor imager.

\section{$B A C$ sequencing and assembly}

The BAC clone GC_Ba0754I06 that covered $170 \mathrm{~kb}$ was bidirectionally shotgun sequenced with an average redundancy of about 6, which was sufficient for assembly and analysis of the entire sequence using previously established procedures [36]. The draft sequence was searched using Blast2 for NSRE1 and NSRE2, BlastN and BlastX against the 'nr' database in GenBank for SINEs/LINEs and CR1-like SINEs/LINEs, respectively. During the BlastX search, at least 27 exons were identified with significant similarity to other species' fatty acid synthase (FASN) exons (E-values of $3 e-56$ and $3 e-46$ to chicken [GenBank:AAB46389] and rat [GenBank:AAA41145], respectively). 


\section{BAC library screening}

The seventeen HDR filters of the BAC library were prehybridized in high-stringency hybridization solution (50\% Formamide, 6x SSC, 0.5\% SDS, 5x Denhardt's solution) [37] supplemented with $100 \mu \mathrm{g} / \mathrm{ml}$ of denatured salmon sperm DNA for $\sim 4$ hours at $42^{\circ} \mathrm{C}$. Probes (50 ng) were radiolabeled using the random-priming method (Roche, Indianapolis, IN) or by incorporating $\alpha^{32} \mathrm{P}-\mathrm{dCTP}$ in the polymerase chain reaction (PCR) [38]. Hybridization was performed overnight at $42^{\circ} \mathrm{C}$ and membranes were washed at room temperature in pre-warmed $\left(42^{\circ} \mathrm{C}\right)$ $2 \mathrm{x}$ SSC/1\% SDS for 20 minutes, followed by washing in $0.2 \mathrm{x}$ SSC/0.1\% SDS for 20 minutes at $65^{\circ} \mathrm{C}$. Membranes were exposed to X-ray film for various lengths of time to obtain positive signals and the desired background. General protocols for high-density BAC library filter screening and address determination of positive signals are publicly available from our website [18]. Putative positive clones were re-spotted on nylon membranes for colony hybridization to confirm true positives. For hybridization with NSRE overgo probes, we performed in the same hybridization solution as described above for Southern Blotting. Filters were washed in $4 \mathrm{x}$ SSC, $0.1 \%$ SDS at room temperature, followed by $0.75 x$ SSC, $0.1 \%$ SDS at $60^{\circ} \mathrm{C}$, exposed to screens, and scanned using the phosphor imager.

\section{Authors' contributions}

RAW, MFF, ML and YO participated in the design of this study. ML constructed the BAC library. ML, YO, HK, DK, NBS, S-JL, CM, KC, AZ, EBB and SMG participated in library characterization and data analysis. KY, HI, and TS participated in sequencing and contig assembly of the BAC clone GC_Ba0754I06. ML, MFF, and YO prepared this manuscript. All authors have read and approved the final manuscript.

\section{Additional material}

\section{Additional File 1}

Analysis of NSRE1 and NSRE2 sequences. GenBank accession numbers containing NSRE1 and NSRE2 identified in this study are listed in this table. Some of them also matched the two nurse shark sequences [GenBank:AF357922] and [GenBank:AF357928]; the length and the \% identities at the nucleotide level are also shown.

Click here for file

[http://www.biomedcentral.com/content/supplementary/14712164-7-106-S1.doc]

\section{Acknowledgements}

We thank Samina Makda, Miriam Eaton, Olin Feuerbacher, Marina Wissotski, Michaela Byrne, Daniel Smart, Diana Stum-Partney and Angelina Angelova for technical assistance and Kiran Rao for data base management. This work was supported by grants from NIH (grants UIHG02525A and Al27877).

\section{References}

I. Miyake T, Amemiya CT: BAC libraries and comparative genomics of aquatic chordate species. Comp Biochem Physiol C Toxicol Pharmacol 2004, I 38:233-244.

2. Osoegawa K, Zhu B, Shu CL, Ren T, Cao Q, Vessere GM, Lutz MM, Jensen-Seaman MI, Zhao S, de Jong PJ: BAC resources for the rat genome project. Genome Res 2004, I 4:780-785.

3. Meyers BC, Scalabrin S, Morgante M: MAPPING AND SEQUENCING COMPLEX GENOMES: LET'S GET PHYSICAL. Nature Reviews Genetics 2004, 5:578-588.

4. Mahairas GG, Wallace JC, Smith K, Swartzell S, Holzman T, Keller A, Shaker R, Furlong J, Young J, Zhao S, Adams MD, Hood L: Sequencetagged connectors: a sequence approach to mapping and scanning the human genome. Proc Natl Acad Sci U S A 1999, 96:9739-9744.

5. Zhao S, Shatsman S, Ayodeji B, Geer K, Tsegaye G, Krol M, Gebregeorgis E, Shvartsbeyn A, Russell D, Overton L, Jiang L, Dimitrov G, Tran K, Shetty J, Malek JA, Feldblyum T, Nierman WC, Fraser CM: Mouse BAC ends quality assessment and sequence analyses. Genome Res 200 I, I I: I736-I745.

6. Marek LF, Mudge J, Darnielle L, Grant D, Hanson N, Paz M, Huihuang $Y$, Denny R, Larson K, Foster-Hartnett D, Cooper A, Danesh D, Larsen D, Schmidt T, Staggs R, Crow JA, Retzel E, Young ND, Shoemaker RC: Soybean genomic survey: BAC-end sequences near RFLP and SSR markers. Genome 200I, 44:572-58I

7. Venter JC, Adams MD, Myers EW, Li PW, Mural RJ, Sutton GG, Smith $\mathrm{HO}$, Yandell M, Evans CA, Holt RA, et al:: The sequence of the human genome. Science 200 I, 29 I: I304-I35I.

8. Green ED: Strategies for the systematic sequencing of complex genomes. Nat Rev Genet 200 I, 2:573-583.

9. Kellner WA, Sullivan RT, Carlson BH, Thomas JW: Uprobe: a genome-wide universal probe resource for comparative physical mapping in vertebrates. Genome Res 2005, 15: I66-173.

10. Botstein $D$, Risch $N$ : Discovering genotypes underlying human phenotypes: past successes for mendelian disease, future approaches for complex disease. Nat Genet 2003, 33:228-237.

II. Gong S, Yang XW, Li C, Heintz N: Highly efficient modification of bacterial artificial chromosomes (BACs) using novel shuttle vectors containing the R6Kgamma origin of replication. Genome Res 2002, I 2:1992-1998.

12. Wing RA, Ammiraju JSS, Luo M, Kim HR, Yu Y, Kudrna D, Goicoechea JL, Wang W, Nelson W, Rao K, Soderlund C, Brar D, Mackill DJ, Han B, Stein L, SanMiguel P, Jackson S: The Oryza Map Alignment Project: The Golden Path to Unlocking the Genetic Potential of Wild Rice Species. Plant Mol Biol 2005, 59:53-62.

13. Luo M, Yu Y, Kim H-R, Kudrna D, Itoh Y, Agate RJ, Melamed E, Goicoechea JL, Talag J, Mueller C, Wang W, Currie J, Sisneros NB, RA W, Arnold AP: Utilization of a Zebra Finch BAC Library to Determine the Structure of an Avian Androgen Receptor Genomic Region. Genomics 2006, 87: I8I-190.

14. Carroll RL: Vertebrate Paleontology and Evolution Freeman, New York; 1988.

15. Flajnik MF: Churchill and the immune system of ectothermic vertebrates. Immunol Rev 1998, 166:5-14.

16. Schwartz FJ, Maddock MM: Cytogenetics of the Elasmobranchs: genome evolution and phylogenetic implication. Marine Freshwater Res 2002, 53:491-502.

17. Ohta Y, Mckinney EC, Criscitiello MF, Flajnik MF: Proteasome, transporter associated with antigen processing, and class I genes in the nurse shark Ginglymostoma cirratum: evidence for a stable class Iregion and MHC haplotype lineages. J Immunol 2002, 168:771-78I.

18. Arizona Genomics Institute [http://www.genome.arizona.edu]

19. Bernstein RM, Schluter SF, Bernstein H, Marchalonis JJ: Primordial emergence of the recombination activating gene I (RAGI): sequence of the complete shark gene indicates homology to microbial integrases. Proc Natl Acad Sci U S A 1996, 93:9454-9459.

20. Kim C-B, Amemiya CT, Bailey W, Kawasaki K, Mezey J, Miller W, Minoshima S, Shimizu N, Wagner G, Ruddle F: Hox cluster genomics in the horn shark, Heterodontus francisci. Proc Natl Acad Sci U S A 2000, 97:1655-1660.

21. Burch JBE, Davis DL, Haas NB: Chicken repeat I elements contain a pol-like open reading frame and belong to the nonlong terminal repeat class of retrotransposons. Proc Natl Acad Soc 1993, 90:8199-8203. 
22. Schluter SF, Marchalonis J]: Cloning of shark RAG2 and characterization of the RAGI/RAG2 gene locus. FASEB J 2003, 17:470-472.

23. Ohta Y, Landis E, Boulay T, Phillips RB, Collet B, Secombes CJ, Flajnik MF, Hansen JD: Homologs of CD83 from elasmobranch and teleost fish. J Immunol 2004, I 73:4553-4560.

24. Terado T, Okamura K, Ohta Y, Shin DH, Smith SL, Hashimoto K, Takemoto T, Nonaka MI, Kimura H, Flajnik MF, Nonaka M: Molecular cloning of $\mathrm{C4}$ gene and identification of the class III complement region in the shark MHC. J Immunol 2003, 171:246I-2466.

25. Amemiya CT, Ota T, Litman GW: Construction of $\mathbf{P I}$ artificial chromosome (PAC) libraries from lower vertebrates. In Analysis of Nonmammalian Genomes Edited by: Lai E, Birren B. San Diego, CA: Academic Press; 1996:223-256.

26. Luo M, Wang Y-H, Frisch D, Joobeur T, Wing RA, Dean RA: Melon bacterial artificial chromosome (BAC) library construction using improved methods and identification of clones linked to the locus conferring resistance to melon Fusarium wilt (Fom-2). Genome 200I, 44:154-162.

27. Clemson University Genomics Institute [http:// www.genome.clemson.edu]

28. Luo M, Wing RA: An improved method for plant BAC library construction. In Plant Fuctional Genomics: Methods and Protocols Volume 236. Edited by: Grotewold E. Totowa, NJ: Humana Press; 2003:3-19.

29. Strong SJ, Ohta Y, Litman GW, Amemiya CT: Marked improvement of PAC and BAC cloning is achieved using electroelution of pulsed-field gel-separated partial digests of genomic DNA. Nucleic Acids Res 1997, 25:3959-396I.

30. Atrazhev AM, Elliott JF: Simplified desalting of ligation reactions immediately prior to electroporation into $E$. coli. Biotechniques 1996, 21:1024.

31. Ewing B, Hillier L, Wendl MC, Green P: Base-calling of automated sequencer traces using phred. I. Accuracy assessment. Genome Res 1998, 8: 175-185.

32. Ewing B, Green P: Base-calling of automated sequencer traces using phred. II. Error probabilities. Genome Res 1998, 8:186-194

33. Rice P, Longden I, Bleasby A: EMBOSS: the European Molecular Biology Open Software Suite. Trends Genet 2000, 16:276-277.

34. Abajian C: SPUTNIK. 1994 [http://espressosoftware.com/pages/ sputnik.jsp].

35. Ross MT, LaBrie S, McPherson JD, Stanton VP: Screening largeinsert libraries by hybridization. In Current Protocols in Human Genetics Edited by: Boyl A. New York: Wiley; 1999:5.6. I-5.6.52.

36. Mizuki N, Ando H, Kimura M, Ohno S, Miyata S, Yamazaki M, Tashiro $\mathrm{H}$, Watanabe K, Ono A, Taguchi S, Sugawara C, Fukuzumi Y, Okumura K, Goto K, Ishihara M, Nakamura S, Yonemoto J, Kikuti YY, Shiina T, Chen L, Ando A, Ikemura T, Inoko H: Nucleotide sequence analysis of the HLA class I region spanning the 237 kb segment around the HLA-B and -C genes. Genomics 1997, 42:55-66.

37. Bartl S, Baish MA, Flajnik MF, Ohta Y: Identification of class I genes in cartilaginous fish, the most ancient group of vertebrates displaying an adaptive immune response. I Immuno 1997, 159:6097-6104.

38. Mertz LM, Rashtchian A: Nucleotide imbalance and polymerase chain reaction: effects on DNA amplification and synthesis of high specific activity radiolabeled DNA probes. Anal Biochem 1994, 221:160-165.

39. Kasahara M, Vazquez M, Sato K, McKinney EC, Flajnik MF: Evolution of the major histocompatibility complex: isolation of class II A cDNA clones from the cartilaginous fish. Proc Natl Acad Sci USA 1992, 89:6688-6692.

40. Bartl S, Weissman IL: Isolation and characterization of major histocompatibility complex class IIB genes from the nurse shark. Proc Natl Acad Sci USA 1994, 9 1:262-266.

4I. Kandil E, Namikawa C, Nonaka M, Greenberg AS, Flajnik MF, Ishibash $\mathrm{T}$, Kasahara M: Isolation of low molecular mass polypeptide complementary DNA clones from primitive vertebrates. Implications for the origin of MHC class I-restricted antigen presentation. J Immunol 1996, I 56:4245-4253.
Publish with Bio Med Central and every scientist can read your work free of charge

"BioMed Central will be the most significant development for disseminating the results of biomedical research in our lifetime. "

Sir Paul Nurse, Cancer Research UK

Your research papers will be:

- available free of charge to the entire biomedical community

- peer reviewed and published immediately upon acceptance

- cited in PubMed and archived on PubMed Central

- yours - you keep the copyright 